\title{
PERANCANGAN SISTEM INFORMASI PENJUALAN BUSANA MUSLIM BERBASIS WEB
}

\section{DESIGN OF WEB-BASED MUSLIM CLOTHING SALES INFORMATION SYSTEM}

\section{S Luckyardi ${ }^{1}$, H Saputra ${ }^{2}$, N Safitri ${ }^{3}$, A Cahyaningrum ${ }^{4}$, D Septiani ${ }^{5}$, R Hidayat ${ }^{6}$, 1,3,4,5 Departemen Manajemen, ${ }^{2,6}$ Departemen Sistem Informasi, Universitas Komputer Indonesia, Bandung, Indonesia Email: herry.saputra@email.unikom.ac.id}

\begin{abstract}
Abstrak
Tujuan dari penelitian ini adalah merancang sebuah sistem informasi pemasaran produk busana muslim dengan konsep marketplace guna menyediakan media belanja online khusus busana muslim. Metode pendekatan sistem yang digunakan yaitu pendekatan berorientasi objek dengan metode pengembangan sistem prototype. media promosi yang dirancang dengan menggunakan teknologi informasi berbasis web sangat diperlukan untuk memudahkan dalam memperoleh informasi konsumen. Berdasarkan hasil penelitian, mempromosikan produk menggunakan website dapat memberikan informasi barang yang akan dijual, laporan data penjualan, dan ketersediaan barang. Sistem informasi ini tentunya akan semakin memudahkan penjual dan pembeli dalam bertransaksi untuk meningkatkan perekonomian penjual dan meningkatkan kebutuhan akan pakaian muslim di kalangan masyarakat.
\end{abstract}

\section{Kata Kunci: Busana Muslim, Pemasaran, Berbasis Web, UMKM}

\begin{abstract}
The purpose of this research is to design a muslim fashion product marketing information system with the concept of a marketplace to provide online shopping media specifically for Muslim fashion. The method of approaching the system used is an object-oriented approach with a prototype system development method. Promotional media designed using web-based information technology is needed to facilitate the obtaining of consumer information. Based on the results of research, promoting products using the website can provide information on goods to be sold, sales data reports, and availability of goods. This information system will certainly make it easier for sellers and buyers to transact to improve the seller's economy and increase the need for Muslim clothing among the public.
\end{abstract}

Keywords: Muslim Clothing, Marketing, Web-based, MS 


\section{PENDAHULUAN}

Indonesia merupakan negara yang sudah masuk kategori negara berkembang menjadi negara maju dalam mengembangkan ekonomi berbasis Sumber Daya Manusia (SDM) dan teknologi berbasis inovasi. Strateginya adalah mengurangi ketergantungan pada pemanfaatan sumber daya alam, meningkatkan kualitas sumber daya manusia, dan meningkatkan wirausaha [1].

Sistem informasi merupakan rangkaian dari subsistem informasi pada pengolahan data sehingga data tersebut akan menghasilkan informasi yang berguna dalam pengambilan keputusan. Yang dimaksud penjualan adalah penjualan barang dagangan oleh masyarakat dan perusahaan yang penjualannya dapat dilakukan secara kredit atau tunai. Dapat disimpulkan bahwa sistem informasi penjualan merupakan sistem yang mengolah transaksi dan data dari semua kegiatan usaha penjualan sehingga tercapai tujuan yang berupa pendapatan. Oleh karena itu, perlu dibuat suatu sistem informasi penjualan yang meliputi transaksi penjualan mulai dari pembuatan faktur, laporan pendapatan, laporan penjualan, dan sistem transaksi yang memudahkan pengguna, serta termasuk juga pengolahan data berupa data pelanggan yang terintegrasi. dengan data penjualan. Perusahaan, organisasi, dan masyarakat dapat mengetahui status barang yang dijual dan mengetahui sejarah penjualan serta kuantitas, tanggal penjualan, dan status penjualan barang. Oleh karena itu, dibuatlah sistem notifikasi yang akan memberi tahu pengguna, dan juga tidak ada sistem penawaran harga [2]. Membahas hasil penjualan busana muslim, terdapat siklus penjualan yang dikenal sebagai rangkaian kegiatan berulang yang diikuti dengan proses pencatatan data dan informasi bisnis. Rangkaian dalam siklus penjualan dimulai dengan menerima pesanan oleh pelanggan, yang diikuti dengan pembungkusan dan pengiriman barang pesanan dan faktur faktur. Oleh karena itu dengan siklus ini dapat disimpulkan bahwa klasifikasi penjualan merupakan salah satu fungsi pemasaran yang sangat penting sehingga sangat menentukan perusahaan dalam mencapai tujuannya yaitu memperoleh laba yang mempertahankan kehidupan usahanya [3, 4]. Di era teknologi saat ini yang prosesnya masih manual selama proses penjualan, konsumen harus datang langsung ke toko, kemudian memilih atau memesan barang yang ingin dibeli dan lain-lain, sehingga invoice untuk pesanan sebelumnya harus segera dikirim ke pelanggan sehingga faktur bisa segera dibuat segera. Melihat proses yang lama dan banyak permasalahan yang akan terjadi, maka sangat diperlukan untuk membuat perancangan sistem informasi penjualan baju muslim dengan menggunakan design use case 
untuk tampilan utama website dan bahasa pemograman yang digunakan untuk menunjang perancangan sistem informasi tersebut [5]. Dengan manajemen yang baik dalam $e$ commerce menggunakan internet yang sangat efektif dalam penjualan, desain ini akan memudahkan dalam penjualan pakaian muslim dan menghindari kesalahan dalam proses manual [6].

Indonesia memiliki penduduk muslim yang banyak, sehingga peminat busana muslim dengan selera fashion yang beragam di berbagai daerah juga akan semakin banyak. Mulai dari produk seperti topi, sajadah, kerudung, sarung, baju muslim, dan lain-lain. Karenanya, banyak yang tergerak dalam bisnis jual beli busana muslim; Selain karena pasarnya yang luas karena peminatnya yang banyak, pakaian muslim juga sangat membantu perekonomian penjual [7]. Usaha Mikro, Kecil, dan Menengah (UMKM) di Indonesia dapat mendukung pembangunan dan perekonomian Indonesia. Oleh karena itu, dengan UMKM ini, kesempatan kerja bagi anak bangsa juga akan meningkat, mendorong perekonomian yang lebih berkeadilan dan memenuhi kebutuhan agar tepat sasaran [8]. Terkait hal ini, pemanfaatan teknologi dan sistem informasi sangat diperlukan untuk optimalisasi peluang pada UMKM bagi peningkatan perekonomian masyarakat. Saat ini UMKM perlu berinovasi pada media penjualan dan memindahkan transaksi pada pasar yang lebih menjanjikan. Pasar tersebut merupakan pasar ecommerce dimana penjual dan pembeli terkoneksi dengan teknologi untuk melakukan transaksi jual-beli. Pasar e-commerce mencakup pelanggan yang lebih luas dibandingkan pasar konvensional sehingga memudahkan akses bagi pembeli yang berada di luar daerah. Selain itu, kemudahan dalam bertransaksi, biaya yang efisien, kecepatan dan komunikasi yang dapat dilakukan setiap saat antara konsumen dan penjual membuat peluang bisnis berbasis website memiliki prospek yang baik. Oleh karena itu penjualan produk fashion perlu dilakukan dengan bantuan sistem informasi dan berbasis web untuk meningkatkan angka penjualan dan profit.

Penelitian ini bertujuan untuk mengetahui peran sistem informasi dalam membantu penjualan busana muslim juga membantu memberdayakan masyarakat. Oleh karena itu penerapan sistem informasi ini dinamakan Sistem Informasi Penjualan Pakaian Muslim berbasis Web. Penelitian ini menggunakan metode deskriptif untuk mendeskripsikan permasalahan masyarakat terlebih dahulu sehingga sistem informasi ini akan meningkatkan kualitas penjualan busana muslim melalui web. [9]. Tentu nantinya web ini akan memuat program-program yang akan 
memudahkan masyarakat untuk menjadi wirausaha, setidaknya pemerintah dapat mengetahui dan mengetahui perkembangan ekonomi masyarakatnya, karena wirausaha adalah roda penggerak perekonomian di setiap daerah.

\section{LANDASAN TEORI}

Berikut ini adalah istilah-istilah atau teori-teori dasar dalam penelitian ini yang tentunya harus peneliti ketahui dan pahami guna untuk melakukan penelitian dengan baik.

\section{Sistem Informasi}

Sistem informasi adalah suatu sistem yang menjadi perantara antara kebutuhan transaksi harian yang mendukung tugas operasional manajemen yang bersifat manajerial berupa strategi untuk dapat menyediakan informasi yang berupa laporan [10].

\section{Unified Modelling Langauge (UML)}

Unified Modelling Language (UML) adalah sebuah "bahasa" yang telah menjadi standar dalam industri untuk visualisasi, merancang dan mendokumentasikan sistem piranti lunak. UML menawarkan sebuah standar untuk merancang model sebuah sistem. Dengan menggunakan UML kita dapat membuat model untuk semua jenis aplikasi piranti lunak, dimana aplikasi tersebut dapat berjalan pada piranti keras, sistem operasi dan jaringan apapun, serta ditulis dalam bahasa pemrograman apapun [11].

\section{Use Case Diagram}

Use case

diagram menggambarkan fungsionalitas yang diharapkan dari sebuah sistem yang dibangun. Apa saja yang tersedia di sistem tersebut dan bagaimana interaksi antar aktor (pengguna sistem). Use case diagram adalah rancangan awal untuk mendesain sistem guna menjadi bahan diskusi kepada pengguna untuk didapatkan evaluasi apa saja yang perlu ditambahkan dan dikurangi [12].

\section{Class Diagram}

Class Diagram adalah diagram yang menggambarkan struktur dari sistem yang sedang dibangun dan dibagi kedalam beberapa kelas. Class diagram merupakan penyederhanaan dari sebuah objek, sehingga class diagram dapat dianggap juga sebagai object diagram [13].

\section{METODE PENELITIAN}

Dalam penelitian ini peneliti menggunakan metode untuk membangun sistem informasi pengajuan akta tanah ini agar berjalan sesuai pedoman pembangunan sistem. Metode pendekatan dan pengembangan yang digunakan dalam penelitian ini adalah pendekatan berorientasi objek dengan pengembangan prototype. 
Metode Pengembangan yang digunakan dalam penelitian ini adalah metode pengembangan sistem prototype. Metode pengembangan prototyping ini berfokus pada kontribusi antara pengguna dengan pengembang aplikasi sehingga dalam pelaksanaannya komunikasi antara keduanya bisa sangat intens untuk mendapatkan hasil yang maksimal. Biasanya pengembang akan menggali informasi kebutuhannya kemudian membuat rancangan tahap awal untuk kemudian menjadi bahan diskusi dan evaluasi dari pengembangan yang dilakukan. Sedangkan dalam perancangan sistem peneliti menggunakan tool seperti use case diagram, database relational dan sebagainya. Berikut adalah langkahlangkah dalam metode pengembangan prototype [14].

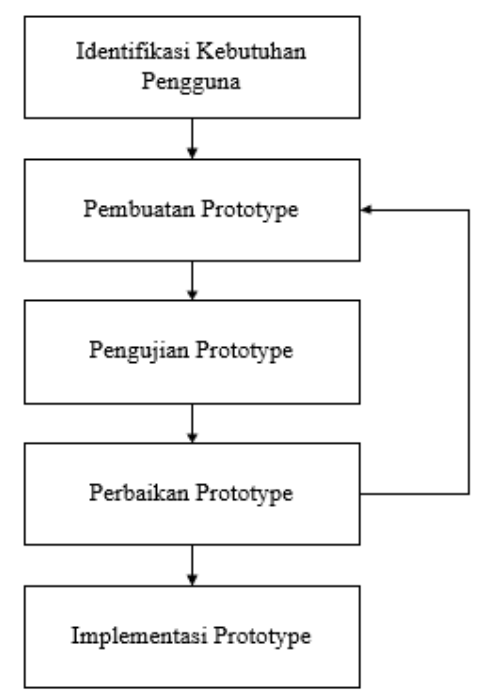

Gambar 1. Metode Pengembangan Prototype

\section{RANCANGAN SISTEM}

Sebelum pengembangan sistem dilakukan, sistem dirancang untuk memastikan bahwa kebutuhan analisis sistem terpenuhi seperti yang diharapkan dalam UML (Unified Modeling Language), yang telah ditetapkan sebagai alat untuk merancang sistem yang diusulkan [15]. Salah satunya dalam UML yang penulis gunakan adalah use case diagram dan class diagram untuk perancangan database. Use case diagram menggambarkan hubungan antar aktor dalam sistem, sehingga dapat menggambarkan suatu proses interaksi antara satu atau lebih aktor dalam perancangan sistem yang dibuat. Disisi lain perancangan basis data merupakan suatu proses yang akan menentukan pengaturan data dan konten yang dibutuhkan untuk mendukung perancangan suatu sistem. Ada dua desain sistem yang dimaksud, yaitu level pertama yang mendesain sistem dengan menganalisis, dan yang kedua adalah desain umum yang dilakukan untuk menentukan kebutuhan pengguna [11].

Penjelasan di atas adalah tools untuk memulai mendesain situs web yang baik dan benar [12]. Dengan begitu, desain yang dibuat akan sangat bagus dan sesuai dengan yang diharapkan. Maka dari itu, memulai perancangan sistem informasi penjualan busana muslim ini, penulis merancang use case untuk membantu mendeskripsikan proses berbasis 
objek pada sistem yang ingin dibuat (lihat gambar 2) [13].

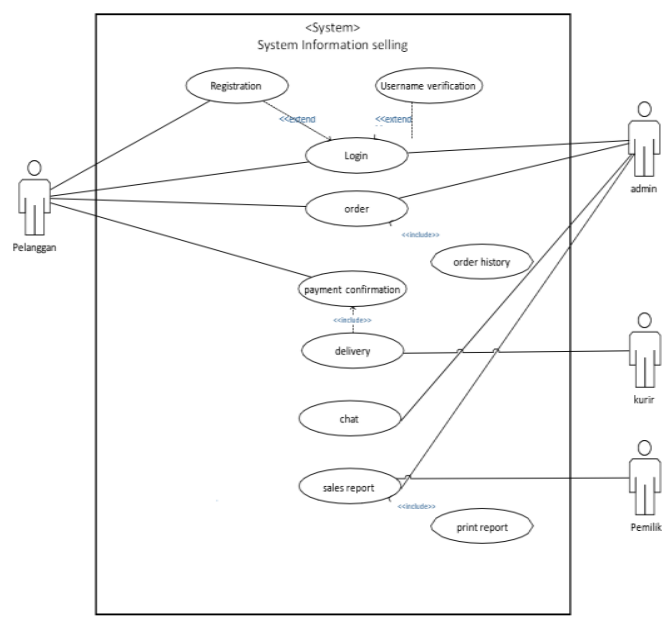

Gambar 2. Use case sistem

Tabel 1 mendeskripsikan masingmasing aktor didalam use case.

Tabel 1. Deskripsi Use case

\begin{tabular}{|c|c|l|}
\hline No & Aktor & \multicolumn{1}{c|}{ Deskripsi } \\
\hline 1. & Pelanggan & $\begin{array}{l}\text { Pelanggan adalah pelaku } \\
\text { yang berinteraksi dengan } \\
\text { hampir semua proses karena } \\
\text { pelanggan adalah pelaku } \\
\text { utama dalam transaksi jual } \\
\text { beli. Baik itu dalam proses } \\
\text { login, proses order, proses } \\
\text { pembayaran, pengiriman, } \\
\text { dan proses penerimaan. }\end{array}$ \\
\hline 2. & Admin & $\begin{array}{l}\text { Admin adalah aktor yang } \\
\text { berinteraksi melalui sistem } \\
\text { dengan pelanggan dan } \\
\text { mengelola sistem web } \\
\text { penjualan. }\end{array}$ \\
\hline 3. & Kurir & $\begin{array}{l}\text { Aktor Kurir memiliki tugas } \\
\text { pada proses pengiriman } \\
\text { barang yang telah dibeli oleh } \\
\text { pelanggan. }\end{array}$ \\
\hline 4. & Pemilik & $\begin{array}{l}\text { Pemilik merupakan pelaku } \\
\text { yang berperan dalam laporan } \\
\text { yang diberikan oleh admin } \\
\text { mengenai penjualan yang } \\
\text { telah dilakukan agar penjualan } \\
\text { dapat tercatat dan dapat } \\
\text { mengecek perkembangan } \\
\text { penjualan. }\end{array}$ \\
\hline
\end{tabular}

Selain itu perancangan sistem menggunakan case dan perancangan database dibuat untuk data yang nantinya akan diinputkan ke dalam sistem dengan cara data penjualan diimplementasikan secara manual. Berikut adalah desain database pada sistem, seperti terlihat pada Gambar 3 [14].

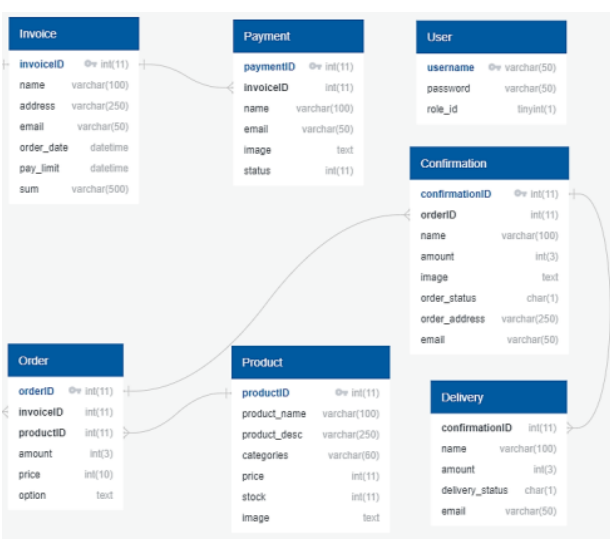

Gambar 3. Normalisasi

Gambar 2 merupakan rancangan basis data yang telah melalui proses normalisasi yang tepat dan dibuat dengan menggunakan diagram kasus sehingga proses-proses dalam sistem saling berhubungan dan oleh basis data. Oleh karena itu, keluaran basis data berupa laporan dan faktur yang sesuai [15], setelah dirancang dan dianalisis mulai dari use case, mendeskripsikan proses yang akan dilakukan oleh sistem dan merancang basis data yang mendeskripsikan setiap data sebagai masukan. atau keluaran dalam sistem.

Pada rancangan database di atas terdapat tujuh tabel dan memiliki atribut masing-masing pada setiap 
tabel. Dan setiap atribut juga memiliki tipe dan nilai berbeda yang telah disesuaikan dan dianalisis sebaik mungkin. Ada tipe integer atau int, yaitu tipe angka, dan ada tipe varchar yang merupakan tipe untuk string yang diketik, yaitu untuk kata atau kalimat, dan ada tipe lain untuk mendukung atribut yang bisa dipanggil bahasa pemrograman [16]. Berikut ini adalah perancangan database berupa normalisasi untuk mengatasi dependensi database:

\section{Normalisasi}

Normalization is the process of identifying the attribute group table which has a high dependence between one attribute and another; the following is an unnormal form:

\section{Bentuk UnNormal}

Sales of Muslim Clothing = \{customer_name, address, phone number, order_status, item_name, price, quantity, total_price, category, picture, stock, email, message_date, pay_limit, delivery status, photo, options

2. Bentuk Normal ke-1

Bentuk normal ke-1 adalah tahap eliminasi duplikasi untuk atribut dalam tabel sehingga setiap atribut hanya memiliki satu nilai. Berikut ini adalah bentuk normal ke-1:

Library $=$ \{customer_name, address, phone number, order_status, item_name, price, quantity, total_price, category, picture, stock, email, message_date, payment_limit, delivery status\}
3. Bentuk Normal ke-2

Bentuk normal ke-2 sudah masuk ke tahap pengelompokan menjadi tabel; setiap kelompok memiliki kunci utama yang berfungsi sebagai kunci untuk mengidentifikasi baris dalam tabel adalah bentuk normal ke-2:

Item $=\{$ item_id $*$, item_name, description, category, price, stock, image

Invoice $=\{\mathrm{id} *$, auction_name, address, email, message_date, payment__limit, total_bayar\} Payment $=\{$ id_payment $*$, name, email, photo, status $\}$

Order $=$ \{order_id, item_name, quantity, price, options

4. Bentuk Normal ke-3

Bentuk Normal ke-3 adalah bentuk akhir dengan menghilangkan anomali yang ada. Bentuk ini didasarkan pada konsep ketergantungan fungsional penuh bentuk normal ke-3:

Customer = \{id_pel *, name_pengunjung, sex_kelamin, types_pengunjung, needs, suggestions $\} \quad$ Product = \{id_barang *, userid **, item_name, description, category, price, stock, image $\}$ Invoice $=\{\mathrm{id}$ *, auction_name, address, email, message_date, payment_limit, total_bayar\} Payment = $\{$ id_payment *, id_invoice **, name, email, photo, status

Order $=\{$ order_id, id_invoice **, item_id ** item_name, quantity, price, options 
Karena adanya normalisasi ini, maka pembentukan diagram desain database seperti gambar di atas melengkapi deskripsi desain database. Selanjutnya adalah perancangan UI (User Interface) pada sistem penjualan berbasis web yang akan dibuat, dimana perancangan UI akan menjelaskan sistem yang dirancang atau dibangun di dalamnya, baik tampilan input maupun outputnya. [17].

\section{IMPLEMENTASI \& PENGUJIAN}

Berikut ini adalah perancangan sistem UI dari sistem informasi penjualan busana muslim berbasis web, seperti terlihat pada Gambar 3.

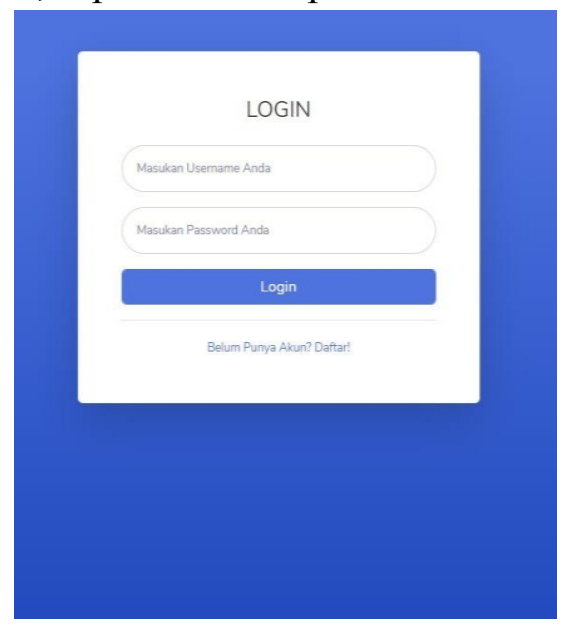

Gambar 3. Halaman Login

Gambar 3 diatas adalah desain user interface dari login yang merupakan proses awal sesuai use case yang dilakukan, dimana pada login ini pelanggan harus masuk dengan menggunakan username dan password yang telah didaftarkan sebelumnya (Gambar 4).
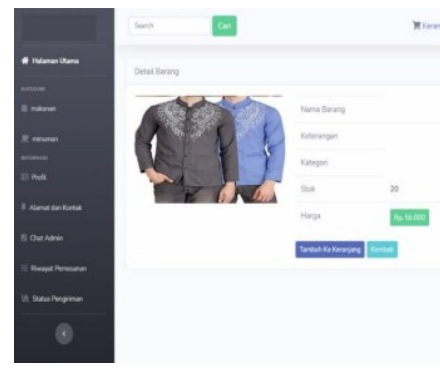

Gambar 4. Halaman Utama

Pada user interface di atas, pelanggan dapat melihat nama dan deskripsi barang atau produk yang dijual serta melihat stok produk. Oleh karena itu, detail barang atau produk ini akan membuat konsumen tertarik untuk membelinya. Di sisi lain, ketika pelanggan berminat untuk membeli, pelanggan dapat langsung membelinya dengan menekan tombol tambah pada gerobak sehingga barang yang ingin dibeli akan masuk ke keranjang sebelum masuk ke proses pemesanan [18] (Gambar 5 ).
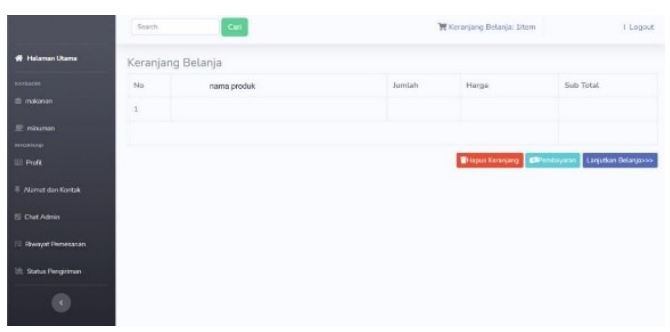

Gambar 5. Halaman Keranjang Belanja

Gambar di atas adalah interface ketika item yang diinginkan telah ditambahkan ke keranjang dan menampilkan nama produk, jumlah, 
harga, dan subtotal dari pembelian. Dan itu bukan hanya satu produk, tetapi berapa pun jumlah produk pakaian muslim yang ingin mereka beli sehingga semuanya akan otomatis masuk ke dalam tabel dan menjumlahkannya secara keseluruhan. Ketika pelanggan tidak membeli produk atau barang yang telah ditambahkan sebelumnya ke keranjang, pelanggan dapat memilih produk yang belum dibeli dan menghapusnya dari keranjang belanja dengan menekan tombol hapus keranjang. Dan saat belanja selesai, pelanggan mengklik tombol pembayaran untuk masuk ke formulir transaksi. Dan jika masih belum puas berbelanja, pelanggan bisa menekan tombol lanjutkan belanja [18] (Gambar 6).
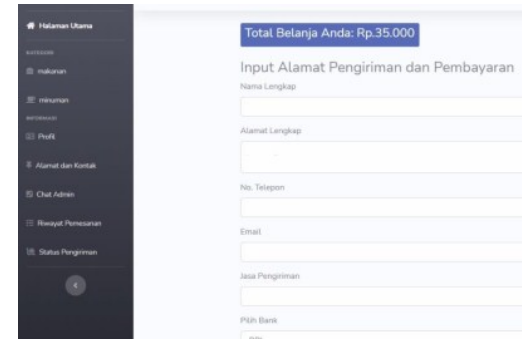

Gambar. 6 Input alamat dan Proses Pembayaran

Pada menu ini, ketika pelanggan telah memilih produk dan telah melalui formulir keranjang belanja, mereka akan masuk ke formulir pemesanan, yang merupakan transaksi inti dari proses penjualan dan pembelian suatu bisnis. Pelanggan diminta untuk mengisi formulir yang tersedia seperti nama, alamat, nomor telepon, email, jenis pembayaran, dan data lainnya. Data yang telah diinputkan akan ditampilkan dalam bentuk detail transaksi (gambar 7).

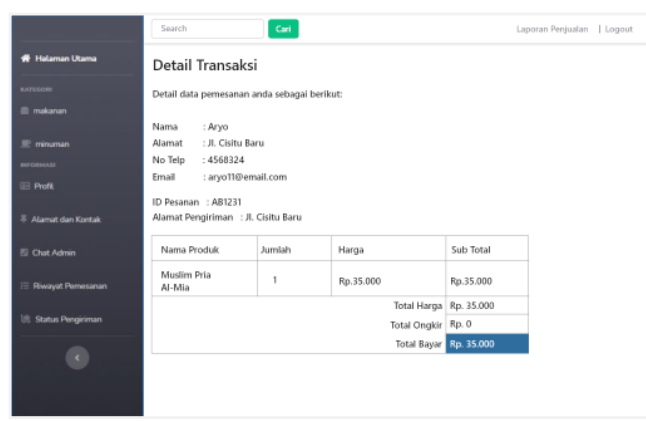

Gambar 7. Detail Transaksi

Halaman diatas menampilkan detail transaksi pelanggan, dan setelah itu pelanggan mengirimkan bukti pembayaran ke tombol pembayaran. Setelah itu pelanggan hanya perlu menunggu konfirmasi dari admin hingga proses pengiriman barang $[19,20]$.

Setelah pelanggan menyelesaikan proses pengisian data dan pembayaran, admin bertugas untuk mengkonfirmasi daftar pesanan yang masuk melalui halaman data penjualan (gambar 8).

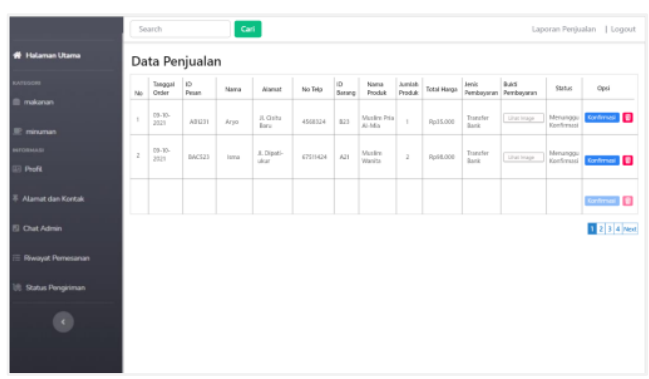

Gambar 8. Data Penjualan 
Transaksi yang telah dikonfirmasi oleh petugas akan dilanjutkan ke proses pengirimin oleh kurir. Seluruh data transaksi yang telah dilakukan dapat dilihat pada menu Laporan penjualan. Admin hanya perlu memilih tanggal awal dan akhir, dan laporan yang ingin ditampilkan (Gambar 9 dan 10).
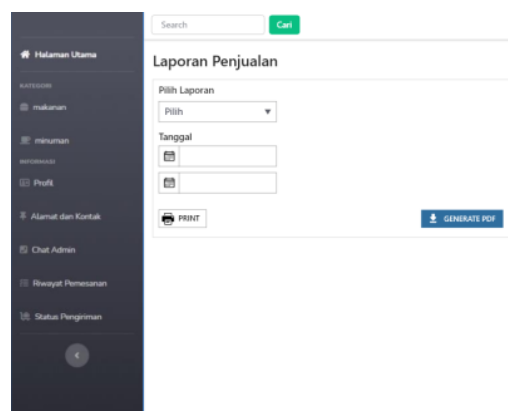

Gambar 9. Halaman Laporan

Penjualan

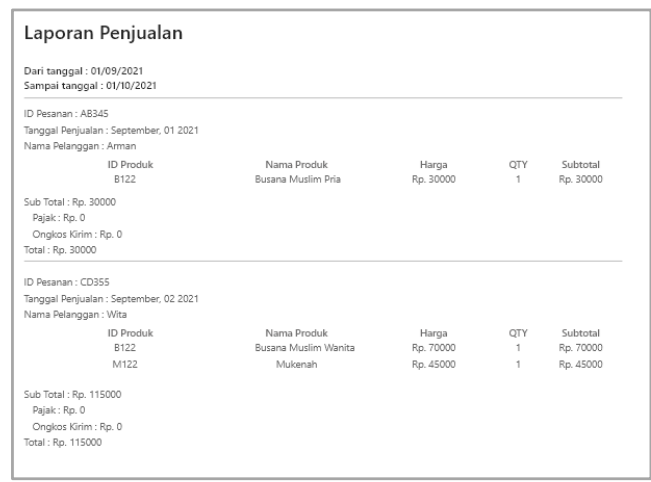

Gambar 10. Cetak Laporan

Selanjutnya sistem yang telah dibangun dilakukan pengujian dengan metode black box testing dengan tujuan melihat fungsionalitas dari sistem tersebut. Berikut adalah hasil pengujian black box testing dapat dilihat pada Tabel 2.
Tabel 2. Black Box Testing Website

\begin{tabular}{|c|c|c|c|}
\hline \multicolumn{4}{|c|}{ Kasus dan Hasil Uji (Data Normal) } \\
\hline $\begin{array}{c}\text { Data } \\
\text { Masuka } \\
\text { n } \\
\end{array}$ & $\begin{array}{c}\text { Hasil yang } \\
\text { Diharapka } \\
\text { n } \\
\end{array}$ & $\begin{array}{c}\text { Pengamat } \\
\text { an }\end{array}$ & $\begin{array}{c}\text { Kesimpul } \\
\text { an }\end{array}$ \\
\hline $\begin{array}{l}\text { Memilih } \\
\text { Simpan } \\
\text { pada } \\
\text { form } \\
\text { Pembaya } \\
\text { ran }\end{array}$ & $\begin{array}{l}\text { Menampilk } \\
\text { an pesan } \\
\text { "Data } \\
\text { Berhasil } \\
\text { Disimpan" }\end{array}$ & $\begin{array}{l}\text { Menampilk } \\
\text { an pesan } \\
\text { "Data } \\
\text { Berhasil } \\
\text { Disimpan" }\end{array}$ & $\begin{array}{l}{[\sqrt{ }]} \\
\text { Diterima } \\
{[\text { ] }} \\
\text { Ditolak }\end{array}$ \\
\hline $\begin{array}{l}\text { Memilih } \\
\text { produk } \\
\text { kemudian } \\
\text { klik } \\
\text { Masukka } \\
\text { n ke } \\
\text { keranjang }\end{array}$ & $\begin{array}{l}\text { Menampilk } \\
\text { an pesan } \\
\text { "berhasil } \\
\text { menambah } \\
\text { kan ke } \\
\text { keranjang" }\end{array}$ & $\begin{array}{l}\text { Menampilk } \\
\text { an pesan } \\
\text { "berhasil } \\
\text { menambah } \\
\text { kan ke } \\
\text { keranjang" }\end{array}$ & $\begin{array}{l}{[\sqrt{ }]} \\
\text { Diterima } \\
{[\text { ] }} \\
\text { Ditolak }\end{array}$ \\
\hline $\begin{array}{l}\text { Mengisi } \\
\text { semua } \\
\text { form } \\
\text { pada } \\
\text { form } \\
\text { login } \\
\text { dengan } \\
\text { akun } \\
\text { yang } \\
\text { sudah } \\
\text { terdaftar }\end{array}$ & $\begin{array}{l}\text { Menampilk } \\
\text { an halaman } \\
\text { utama } \\
\text { website }\end{array}$ & $\begin{array}{l}\text { Menampilk } \\
\text { an halaman } \\
\text { utama } \\
\text { website }\end{array}$ & $\begin{array}{l}{[\sqrt{ }]} \\
\text { Diterima } \\
{[\text { ] }} \\
\text { Ditolak }\end{array}$ \\
\hline $\begin{array}{l}\text { Mengisi } \\
\text { form } \\
\text { login } \\
\text { dengan } \\
\text { akun } \\
\text { yang } \\
\text { belum } \\
\text { terdaftar }\end{array}$ & $\begin{array}{l}\text { Menampilk } \\
\text { an pesan } \\
\text { "Akun } \\
\text { yang anda } \\
\text { masukkan } \\
\text { salah" }\end{array}$ & $\begin{array}{l}\text { Menampilk } \\
\text { an pesan } \\
\text { "Akun } \\
\text { yang anda } \\
\text { masukkan } \\
\text { salah" }\end{array}$ & $\begin{array}{l}{[\sqrt{ }]} \\
\text { Diterima } \\
{[\text { ] }} \\
\text { Ditolak }\end{array}$ \\
\hline
\end{tabular}

\section{KESIMPULAN}

Perkembangan

teknologi

meningkat pesat. Dalam hal ini akan membuat pemerintah mencari cara untuk meningkatkan perekonomian khususnya penjualan dengan memanfaatkan teknologi dengan menggunakan aplikasi berbasis web ini. Aplikasi ini nantinya akan membantu mensosialisasikan program-program yang dapat meningkatkan perekonomian salah satunya adalah program yang dapat mempermudah dan mengembangkan sumber daya masyarakat untuk 
menjadi wirausaha. Sebab, peningkatan wirausaha di suatu negara akan meningkatkan perekonomian negara tersebut. Selain sosialisasi langsung, sosialisasi melalui website merupakan salah satu cara yang paling efektif karena dengan menggunakan website akan mempermudah dan mempercepat dalam menyimpan informasi secara lengkap.

\section{DAFTAR PUSTAKA}

[1] Soegoto. Eddy Soeryanto. 2014, Entrepreneurship Becomes an Excellent Businessman. Second Edition, Jakarta: PT. Elek Media Komputindo.

[2] Sugimoto, M., Watanabe, M., Makishima, S., Kawaoka, Y., Shinkai, Y., Namiki, A., \& Kaku, T. 2004. U.S. Patent No. 6,687,608. Washington, DC: U.S. Patent and Trademark Office.

[3] Ardana, I. C., \& Lukman, H. 2016. Accounting information system. Jakarta: Mitra Wacana Media.

[4] Adams, Mike. "Investment earnings and the characteristics of life insurance firms: New Zealand evidence." Australian Journal of Management, 21(1), pp.41-55.

[5] Kom, A. M. 2020. Perancangan Aplikasi Web Penjualan Pakaian Muslim. SIMADA (Jurnal Sistem Informasi dan Manajemen Basis Data), 3(1), pp.1-16.
[6] Nugraha, A., \& Octasia, A. 2016. Web-Based Information System for T-Shirt Sales in EcommerceBased Sickness Distro.

[7] Yuli R S. 2017. Development of MSMEs (Micro, Small and Medium Enterprises) in Indonesia.

[8] Supriyatna, and Agus Tina. 2017. Website Design For Promotion And Sales Media. Indonesian Journal on Networking and Security, 6(1).

[9] Bates, D. W., Pappius, E., Kuperman, G. J., Sittig, D., Burstin, H., Fairchild, D., ... \& Teich, J. M. 1999. Using information systems to measure and improve quality. International journal of medical informatics, 53(2-3), pp.115-124.

[10] Sutabri, Tata. Konsep sistem informasi. Penerbit Andi, 2012.

[11] Kanai, H., \& Kumazawa, A. (2021). An Information Sharing System for Multi-Professional Collaboration in the community-based integrated healthcare

system. International Journal of Informatics, Information System and Computer Engineering (INJIISCOM), 2(1), 1-14.

[12] Susanto Anna Dara Andriana, Rani. "Perbandingan model waterfall dan prototyping untuk pengembangan sistem 
informasi." Majalah Ilmiah UNIKOM (2016).

[13] Pangaribuan, I., Rahman, A., \& Mauluddin, S. (2020). Computer \& Network Equipment Management System (CNEMAS) Application Measurement. International Journal of Informatics, Information System and Computer Engineering (INJIISCOM), 1, 23-34.

[14] Ginting, S. L. B., Maulana, H., Priatna, R. A., Fauzzan, D. D., \& Setiawan, D. (2021). Crowd Detection Using YOLOv3-Tiny Method and Viola-Jones Algorithm at Mall. International Journal of Informatics, Information System and Computer Engineering (INJIISCOM), 2(2), 13-22.

[15] Saleh, A., Ariamin, Pawennari, A., \& Padhil, A. 2018. Designing Sales Administration Management Information System at Lintang Outdoor Web-Based Stores.

[16] Maulana, Iqbal. 2015. Designing Information Systems for Cash Sales of Textile Applications at $P D$. The youngest son of Djaya Jakarta. Indonesian Journal on Software Engineering, 3(2).

[17] Zhang, P., Small, R. V., Von Dran, G. M., \& Barcellos, S. 2000. A two factor theory for website design. In Proceedings of the 33rd Annual Hawaii International Conference on System Sciences (pp. 10-pp). IEEE.

[18] Ibrahim, N., Ibrahim, R., Saringat, M. Z., Mansor, D., \& Herawan, T. 2011. Definition of consistency rules between UML use case and activity diagram. In International Conference on Ubiquitous Computing and Multimedia Applications (pp. 498-508). Springer, Berlin, Heidelberg.

[19] Demuth, B., \& Hussmann, H. 1999. Using UML/OCL constraints for relational database design. In International Conference on the Unified Modeling Language (pp. 598-613). Springer, Berlin, Heidelberg.

[20] Lee, H. 1995. Justifying database normalization: a cost/benefit

model. Information processing \& management, 31(1), pp.5967.

[21] Demba, M. 2013. Algorithm for relational database normalization up to $3 N F$. International Journal of Database Management Systems, 5(3), pp.39.

[22] Leone, S., \& Norrie, M. C. 2011. Building eCommerce systems from shared micro-schemas. In OTM Confederated 
International Conferences" On the Move to Meaningful Internet Systems" (pp. 284301). Springer, Berlin, Heidelberg.

[23] Pratt, A., \& Nunes, J. 2012. Interactive design: An introduction to the theory and application of user-centered design. Rockport Pub.

[24] Laudon, K. C., \& Traver, C. G. 2016. E-commerce: business, technology, society.

[25] Deng, L., \& Poole, M. S. 2012. Aesthetic design of ecommerce web pagesWebpage Complexity, Order and preference. Electronic Commerce Research and Applications, 11(4), pp.420440. 